Research Article

\title{
Teaching Reform of "Work-Integrated Learning” in International Trade Practice from the Perspective of BDaaS
}

\author{
Yiting Zhu \\ School of Foreign Languages, Wuhan University of Bioengineering, Wuhan 430415, China \\ Correspondence should be addressed to Yiting Zhu; janezhu@whsw.edu.cn
}

Received 25 October 2021; Revised 25 November 2021; Accepted 7 December 2021; Published 23 December 2021

Academic Editor: Qiangyi Li

Copyright $\odot 2021$ Yiting Zhu. This is an open access article distributed under the Creative Commons Attribution License, which permits unrestricted use, distribution, and reproduction in any medium, provided the original work is properly cited.

To improve the reform performance of international trade practice, the method with perspective of big data is researched in this study. The international trade professional is developing rapidly to keep pace with social development gradually. With the further development of the society, the traditional international trade major exposed some shortcomings, such as course training target, content and teaching method, and so on, which have fallen behind the progress of society. However, the perspective BDaaS is applied in this study to solve this problem, and the experiment results show that the proposed method will effectively improve the ability of cultivating international trade professionals.

\section{Introduction}

With the development and progress of social economy, China's foreign trade volume continues to grow, and the demand for international trade talents is increasing day by day. Especially, talents with high professional quality, strong comprehensive ability, and rich international trade experience are favored. Although the supply and demand of foreign trade enterprises and international trade professionals are booming, the employment rate of international trade undergraduates is not high. The reason is that on the one hand, the labors' requirement amount is raising; on the other hand, the current teaching modal and training manners cannot provide plenty of the qualified labors [1].

"International Trade Practice" is one of the center classes of the international trade profession in application-oriented university. With the characteristics of foreign-related activities, "International Trade Practice," a study of the process of international exchange of commodities subject, is a highly comprehensive practical application of course. This course is practical, profession related, and wide-ranged. During a long period, a modal has been formed gradually. Under this modal, the student's progress is slow, and the effect is bad. The students cannot understand some terminologies, and their comprehension is limited in theory level, but their abilities to resolve problems are low. So, the modal is not successful $[2,3]$. Leaders in foreign trade corporations hold the students' professional competence in suspicion and will not offer opportunities to them to experience the relevant positions, even though the students have studied the relative classes for more than 4 years.

Big data closely combined with the development of the times can provide real data and practice cases synchronized with the industry from the aspects of the economic development trend, industry reform process, and actual operation process. Not only in the process of informatization, big data and the Internet have played a pivotal role in technological innovation, economic model innovation, and transparency of government work. Different from traditional big data, Big Data-as-a-Service (BDaaS) integrates data source, data processing, and data application. Three respects are combined together organically to develop the multiplier effect. Data sources can be limited official databases such as government departments or unlimited virtual databases such as Blogs, WeChat, or even personal websites. Big data processing involves acquisition, storage, processing, research, prediction, and result presentation. This shows that big data is an application data technology that obtains valuable information through various ways and analyzes data for specific purposes [4]. Only when data objects, data 
technologies, and data applications cooperate with each other can the maximum effect of big data be realized. The close cooperation between big data and industry will bring economic prosperity to specific fields. Therefore, big data innovation has a huge market prospect.

In this study, the perspective of "Work-Integrated Learning" combining with big data is applied to solve this problem.

\section{The "Work-Integrated Learning" Reform of "International Trade Practice"}

Many failures in practical teaching planning result in the misunderstanding of practical talents:

(1) Overemphasize language and intercultural communication capability. This leads to blind application of bilingual teaching, overemphasizing English terminologies, but neglecting trade knowledge and professional capabilities. We believe communication is basic but not core for this course.

(2) Mistake operational talents as practical talents. Many practical teachings are in fact pure operational trainings. They take operational capabilities of merchandiser, customs declarer, and coordinators as the only object of talent cultivation, neglecting the comprehensive capability of international business management. In this case, talents are only capable to deal with the operational issues but are vulnerable to market risks.

(3) Neglect the importance of comprehensive capability of international business management. The highlevel talents should have a strategic vision, risk control capability, capital management ability, leadership, information processing capacity, and decision-making ability. These management capabilities can only be acquired from practice with real risks.

There are three types of practical teaching for international trade: in-class simulation, computer simulation, and on-job practice (all with deficiencies).

First, in-class simulation can only simulate fragmented operations. Take B/L as an example. Students play the role of shipper, carrier, and bank to finish the cargo delivery, issue of $\mathrm{B} / \mathrm{L}$, and negotiation. In-class simulation is easy and practical, but can only practice fragmented operations and fail to stimulate students' enthusiasm.

Second, computer simulation is facility demanding and fails to simulate the real market risk. It is popular nowadays for colleges to invest huge sum on computer simulation software in the trend of practical reforms, thinking that it is the best way to practical teaching. There are also many teaching software for choice, such as document platform and trade practical platform. However, further research finds that computer simulation has three discrepancies:

(1) Trade teaching software is expensive and facility demanding (e.g., computer labs and Internet access). Not all colleges can afford it. Once they risk huge investment on the software and facilities, colleges tend to overvalue the effectiveness of computer teaching.

(2) Most software on the market is the pure trade process and operation simulation. They fail to introduce the real international market risk and business environment. Students can get familiar with import and export processes and operations and documents but fail to practice their abilities of risk management, decision making, and strategic vision. Software is good for operational talent cultivation but poor for high-level comprehensive management talent cultivation.

(3) The evaluation system of computer simulation is based on correctness of documents and process fulfillment. It fails to offer role play and teamwork. Student score has nothing to do with business success which results in negligence of business risks.

Third, on-job training is infeasible. On-job training is the other extreme against "theory standard" It believes that practical capabilities can only learn from real practices. Therefore, practical teaching can only be carried out on job. Students need to go to industry as interns and get instructions from professional tutors. They practice in the real import and export business and learn knowledge from practices. This is a perfect idea but infeasible in today's China. Enterprises are profit-oriented, but not training organizations for green hands.

According to the above objects and problems of practical teaching, we put forward an innovated plan. We believe that cultivating talents with 3-layer capabilities, including basic capability of intercultural communication, professional capability of trading operations, and comprehensive capability of international business management, are the key objects of this course. In the course of daily teaching, targeted practice is an important method to cultivate students' professional core competitiveness. Moreover, international trade operations and management are highly specialized; talents cannot be omnipotent. It is important for students to know their strengths and weaknesses and settle their roles in future career. It is also important for them to build up teamwork spirit within the organization and to be cooperative with other business partners. This plan integrates teaching, learning, and practicing to trigger autonomic learning and independent thinking. It targets at cultivating basic, professional, and comprehensive capabilities of students; we integrate bilingual teaching in the process of practical training to enhance basic communication ability; we achieve practical teaching for the whole import and export operations by organizing student teams to compete in practical fair; and we practice their international business management capability by incorporating risks. The evaluation system is based on behavior effectiveness including business success and operation correctness. This highly stimulates students' autonomic learning and enthusiasm of teamwork participation. This plan achieves four innovations in teaching reforms. 
First, introduce the behavior-oriented teaching method to promote autonomic learning. Since 1980s, Germany has pioneered for college. This teaching method is based on activity-oriented, competency-based teaching. The objective is to train students in critical capabilities to enable them to cultivate an interest in the activity. Actively motivated to learn, students learn to become the masters of the classroom. Its approach is to require students to study not only with the brain but also the brain, heart, and hand to participate in learning, improving their capacity to act. We apply this method to international trade teaching, build up a simulated transaction market, ask students to set up: simulated company," and learn and practice in their "operational post." Here, score risk takes the place of business risk which encourages students to be careful and responsible in their position.

Second, introduce "simulated company," create "simulated market" to practice international business management abilities, and build up teamwork spirit. "Simulated company" concept began in 1950s in Germany. In this teaching method, students are setting up virtual companies and run their businesses in an autarky economy. They do businesses with other simulated companies and carry out real business operations except for product and money. Students can shift among different posts and practice the whole process of business operation. During the practice, students get to know the business relations undertaking no economic risks. We introduce the "simulated company" teaching method in our plan. Students are bound to set up an import and export company. Every team plays 3 roles, as exporter, purchaser, and shipping company.

The basic algorithm for simulating the company's data is as follows [5]:

$$
\varphi_{j i}\left(\mu_{j}\right)=\exp \left(\frac{-\left(\mu_{j}-C_{j i}\right)^{2}}{b_{j i}^{2}}\right), \quad \text { for } i=1,2, \ldots, H \text {. }
$$

In this space, the $m^{\text {th }}$ multidimensional receptive-field function is defined as

$$
\Phi_{m}(\mu)=\prod_{j=1}^{L} \varphi_{j i}\left(\mu_{j}\right), \quad \text { for } m=1,2, \ldots, N .
$$

The function can be written in a vector notation as

$$
\Phi(\mu, C, b)=\left[\Phi_{1}, \Phi_{m}, \ldots, \Phi_{N}\right]^{T},
$$

where $C=\left[C_{11}, \ldots, C_{L 1}, C_{12}, \ldots, C_{L 2}, \ldots, C_{1 H}, \ldots C_{L H}\right]^{T}$.

The weight storage space with $N$ components can be represented in a vector as

$$
W=\left[W_{1}, W_{m}, \ldots, W_{N}\right]^{T} .
$$

The activated weights in weight storage space can be written in a vector form as

$$
y=W^{T} \Phi(\mu) .
$$

The state variables and the desired values can be defined as follows:

$$
z_{1}=x_{1}-y_{d}
$$

and

$$
z_{2}=x_{2}-\alpha_{1}
$$

The following tracking error dynamics is expressed as

$$
\dot{z}_{1}=\dot{x}_{1}-\dot{y}_{d}=x_{2}-\dot{y}_{d}=z_{2}+\alpha_{1}-\dot{y}_{d} \text {. }
$$

The first derivative of the Lyapunov function can be written as

$$
\begin{aligned}
\dot{V}_{1} & =z_{1}^{T} \dot{z}_{1}=z_{1}^{T}\left(\dot{x}_{1}-\dot{y}_{d}\right)=z_{1}^{T}\left(\dot{x}_{1}-\dot{y}_{d}\right) \\
& =z_{1}^{T}\left(x_{2}-\dot{y}_{d}\right)=z_{1}^{T}\left(z_{2}+\alpha_{1}-\dot{y}_{d}\right)=-\lambda_{1} z_{1}^{T} z_{1}+z_{1}^{T} z_{2} .
\end{aligned}
$$

From (2) and (6), it can be obtained:

$$
\dot{z}_{2}=\dot{x}_{2}-\dot{\alpha}_{1}=-M^{-1} C x_{2}-M^{-1}\left(G_{g}+d\right)+M^{-1} \tau-\dot{\alpha}_{1} \text {. }
$$

$\tau$ is selected as

$$
\tau=-\lambda_{2} z_{2}-z_{1}-F .
$$

Then, we can get

$$
\begin{aligned}
V_{2} & =V_{1}+\frac{1}{2} z_{2}^{T} M z_{2}, \\
\dot{V}_{2} & =\dot{V}_{1}+\frac{1}{2} z_{2}^{T} M \dot{z}_{2}+\frac{1}{2} \dot{z}_{2}^{T} M z_{2}+\frac{1}{2} z_{2}^{T} \dot{M} z_{2}, \\
& =-\lambda_{1} z_{1}^{T} z_{1}+z_{1}^{T} z_{2}+z_{2}^{T} M\left(\dot{x}_{2}-\dot{\alpha}_{1}\right)+z_{2}^{T} C z_{2} \\
& =-\lambda_{1} z_{1}^{T} z_{1}+z_{1}^{T} z_{2}+z_{2}^{T}\left(-C x_{2}+C z_{2}+\tau-M \dot{\alpha}_{1}-\left(G_{g}+d\right)\right) \\
& =-\lambda_{1} z_{1}^{T} z_{1}+z_{1}^{T} z_{2}+z_{2}^{T}(f+\tau)-z_{2}^{T}\left(G_{g}+d\right),
\end{aligned}
$$




$$
\begin{aligned}
\dot{V}_{2} & =\dot{V}_{1}+\frac{1}{2} z_{2}^{T} M \dot{z}_{2}+\frac{1}{2} \dot{z}_{2}^{T} M z_{2}+\frac{1}{2} z_{2}^{T} \dot{M} z_{2} \\
& =-\lambda_{1} z_{1}^{T} z_{1}+z_{1}^{T} z_{2}+z_{2}^{T} M\left(\dot{x}_{2}-\dot{\alpha}_{1}\right)+z_{2}^{T} C z_{2} \\
& =-\lambda_{1} z_{1}^{T} z_{1}+z_{1}^{T} z_{2}+z_{2}^{T}\left(-C x_{2}+C z_{2}+\tau-M \dot{\alpha}_{1}-\left(G_{g}+d\right)\right) \\
& =-\lambda_{1} z_{1}^{T} z_{1}+z_{1} z_{1}^{T} z_{2}+z_{2}^{T}(f+\tau)-z_{2}^{T}\left(G_{g}+d\right), \\
\dot{V}_{2} & =-\lambda_{1} z_{1}^{T} z_{1}-\lambda_{2} z_{2}^{T} z_{2}+z_{2}^{T}(f-F)-z_{2}^{T}\left(G_{g}+d\right) .
\end{aligned}
$$

The ideal weight $W$ is from (10) and expressed as

$$
F=W^{T} \Phi(\mu) \text {. }
$$

Define the estimate of the value of (11) as

$$
\widehat{F}=\widehat{W}^{T} \Phi(\mu) \text {. }
$$

Student teams carry out market research and product design, participate trade exhibition, and sign up contracts. According to the sales contract and carriage contract, they fulfill the operations and related documents of delivery, shipment, insurance, customs clearance, and payment. It achieves practical teaching for the whole trading process. Student teams compete in this autarky international market. To be more real, we creatively set up two simulated markets of "export market" and "sales market." Export price and sale price are directed by the "visible hands" of the tutor team.

Third, introduce the situational teaching method to reform the traditional concepts and break the restrains of teaching facilities. Situational teaching is to create a simulated situation where students can practice to refine behaviors and target career. Only when students are in the specific situation of certain knowledge, significant learning is possible. Knowledge acquired under these circumstances is most complete, powerful, and usable. This plan helps students to set up company teams and participate in international trade. Students are "learning by doing" in these situations. In order to succeed in business, students are active to learn, to think, and to consult their tutors. This largely reforms the passive traditional teaching method. Moreover, transitions center on "Simulated Canton Fair." Universities can use computer simulation or manual setting of this situation, freeing from facility restrains [6].

Fourth, practical fair situation bridges school and industry. With more than 100 times, Canton Fairs become the most important trade platform in Canton (even in China). Many manufacturers get $1 / 3$ of their orders of the whole year during the exhibit. Canton Fair is a platform that suppliers, buyers, and all kinds of trade intermediaries meet. It is also a big show of comprehensive business skills. Practical fair highly simulates the real international trade transactions. Centering international trade flow and operations at this point can give students a good opportunity to practice their trade skills and competences. It also significantly shortens the distance between school and industry.

\section{The Advantages of "Work-Integrated Learning" Combining with Big Data}

Integrating big data into teaching is an important direction in the transformation of the current teaching mode. Hadoop in BDaaS can be used to collect data, analyze data, and predict the development trend of the industry by using data, so as to predict the needs of enterprises in advance and build a bridge between enterprise development and talent training. Big Data-as-a-Service (BDaaS) is a new way to use information, which can effectively serve teaching. Through data Encapsulation and heterogeneous data, data can be used in the teaching of international trade courses. Through search, analysis, and visual processing, the data can provide teachers and students with more intuitive teaching experience and timely and convenient teaching resources support [7-9]. The following advantages will be emerged when big data combine with international trade practice teaching:

(1) Realizing data collection of students' autonomous learning behavior. "Combination of work and study" can promote the transformation of student-centered teaching mode. BDaaS can be used to collect the information of students' autonomous learning behavior.

(2) BDaaS uses Hadoop software framework and MapReduce technology to help universities select relevant information from mass information for practical teaching activities (Figure 1)

(3) Realizing data mining and guiding the purpose of simulation teaching. Data mining can find potential, unknown, and helpful relationships from huge data and guide students to complete the activities of simulated companies and Canton Fair.

\section{The Experiment and Innovated Teaching Plan of "Work-Integrated Learning" Combining with Big Data}

The practical teaching mode of "Work-Integrated Learning" and big data can provide new ideas for the teaching reform of international trade major. Based on this concept, this study designs a set of feasible teaching implementation plan, including 4 teaching modules and 13 links as follows:

Module I: knowledge of international trade practices. It includes 4 areas including trade knowledge, business processes and related documents, document making, and 


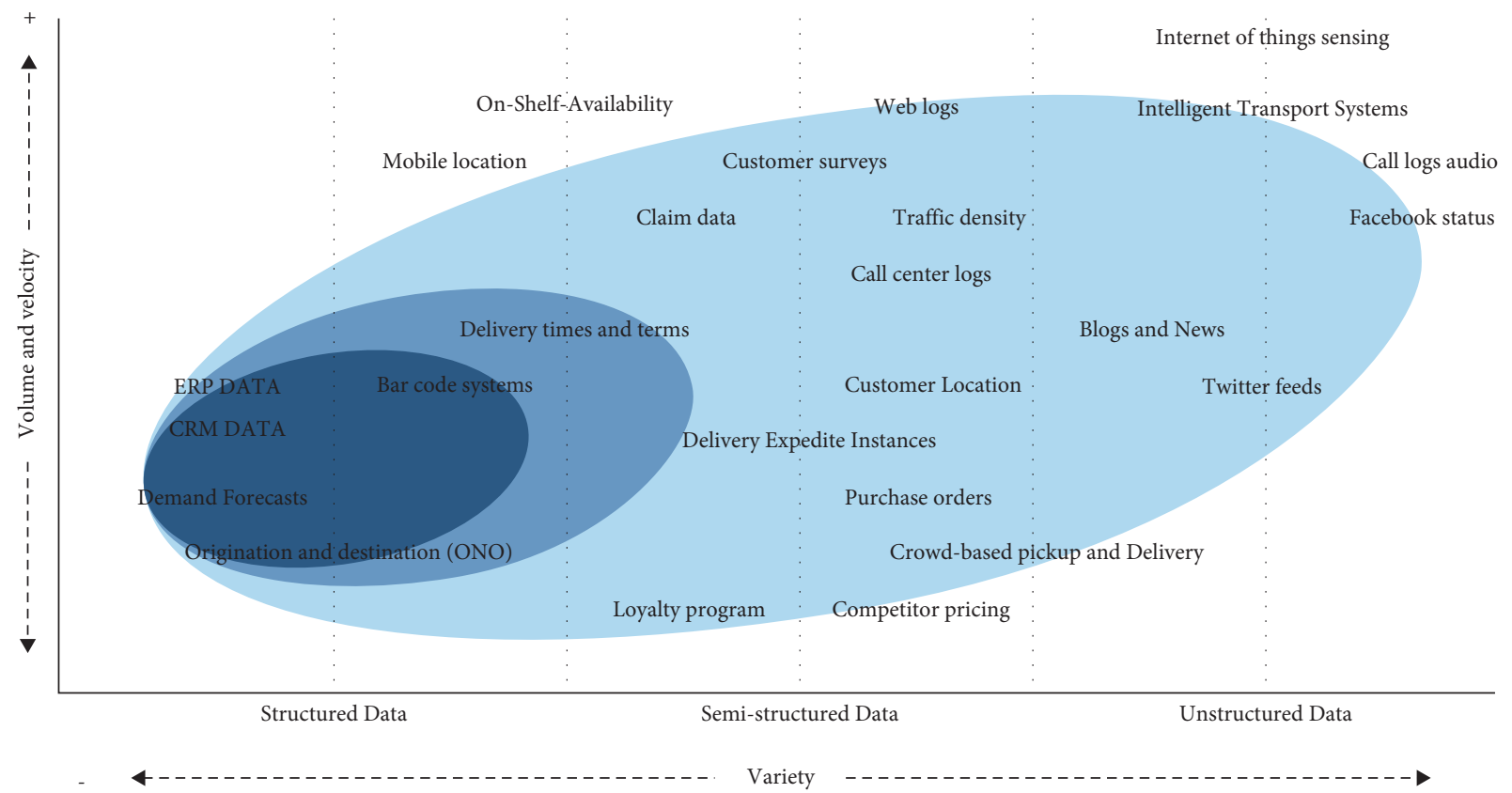

Figure 1: The situation of big data source and volume in development.
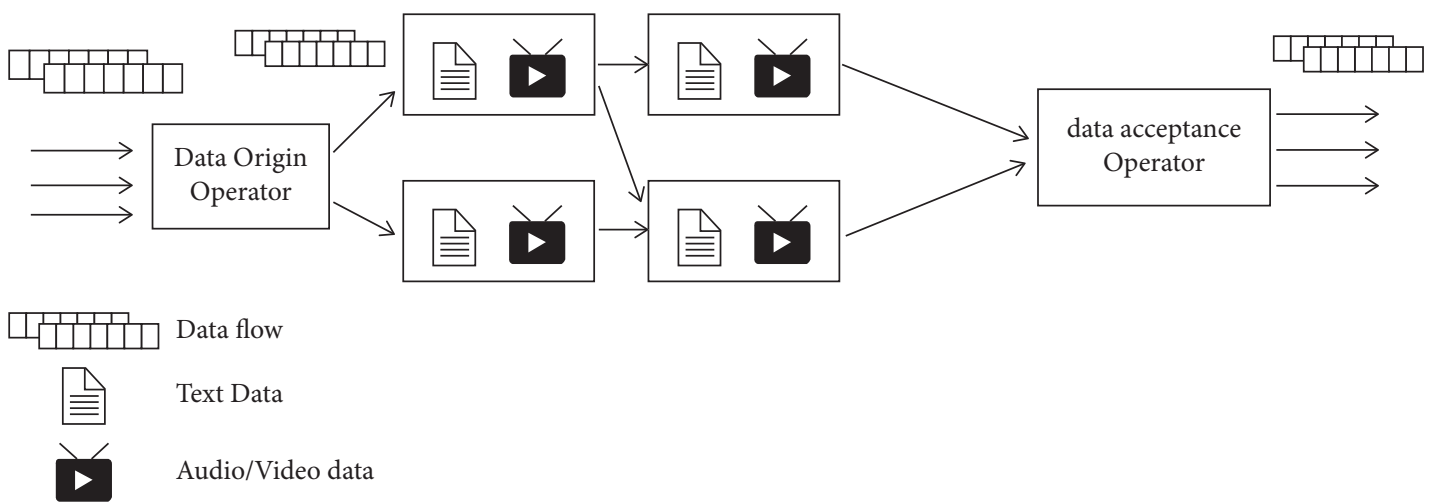

FIGURE 2: Abstract model of teaching data dynamic generation and service composition.

requirements and business negotiation skills. In this stage, tutors should use BDaaS to collect the most important work in the process of enterprise operation and focus on explaining theoretical knowledge.

Module II: construction of simulated market and simulated company. It includes setting up simulated company teams, settling down products and quotations, and preparing for exhibits. In this stage, the big data supplier develops data service modeling, dynamic generation, service composition, and other functions based on the data service engine (DSE), as shown in Figure 2. Then, tutors will use BDaaS data mining and visualization functions to design VR scenarios and assist students to make decisions and implementation methods conducive to the development of the company in the simulation scenarios.

Module III: simulated Canton Fair. Simulated companies exhibit products and sign up sales and carriage contracts. They also finish the operations and related documents of delivery, shipment, insurance, customs clearance, inspection, payment, and tax rebates. In this stage, according to the requirements of the course, BDaaS suppliers simplify the attributes of video resources related to the Canton Fair, combine the attributes with similar meanings, and establish an unstructured data model to restore the information of commodity types, customer sources, site layout, and transaction methods of the Canton Fair.

Module IV: practices evaluation and case analysis. Tutors evaluate students' business performance and write evaluation report. Students view the video of their transaction and make group presentation to share experiences and failures. Tutors make further comments and analyze typical case to shed light on trade knowledge and business management competences. Finally, the tutors use the behavior analysis function of the BDaaS system to analyze and refine the video materials, contracts, transaction credentials, and performance reports generated by students performing the above tasks and finally obtains the evaluation report of practical teaching for guiding the next stage of teaching. 


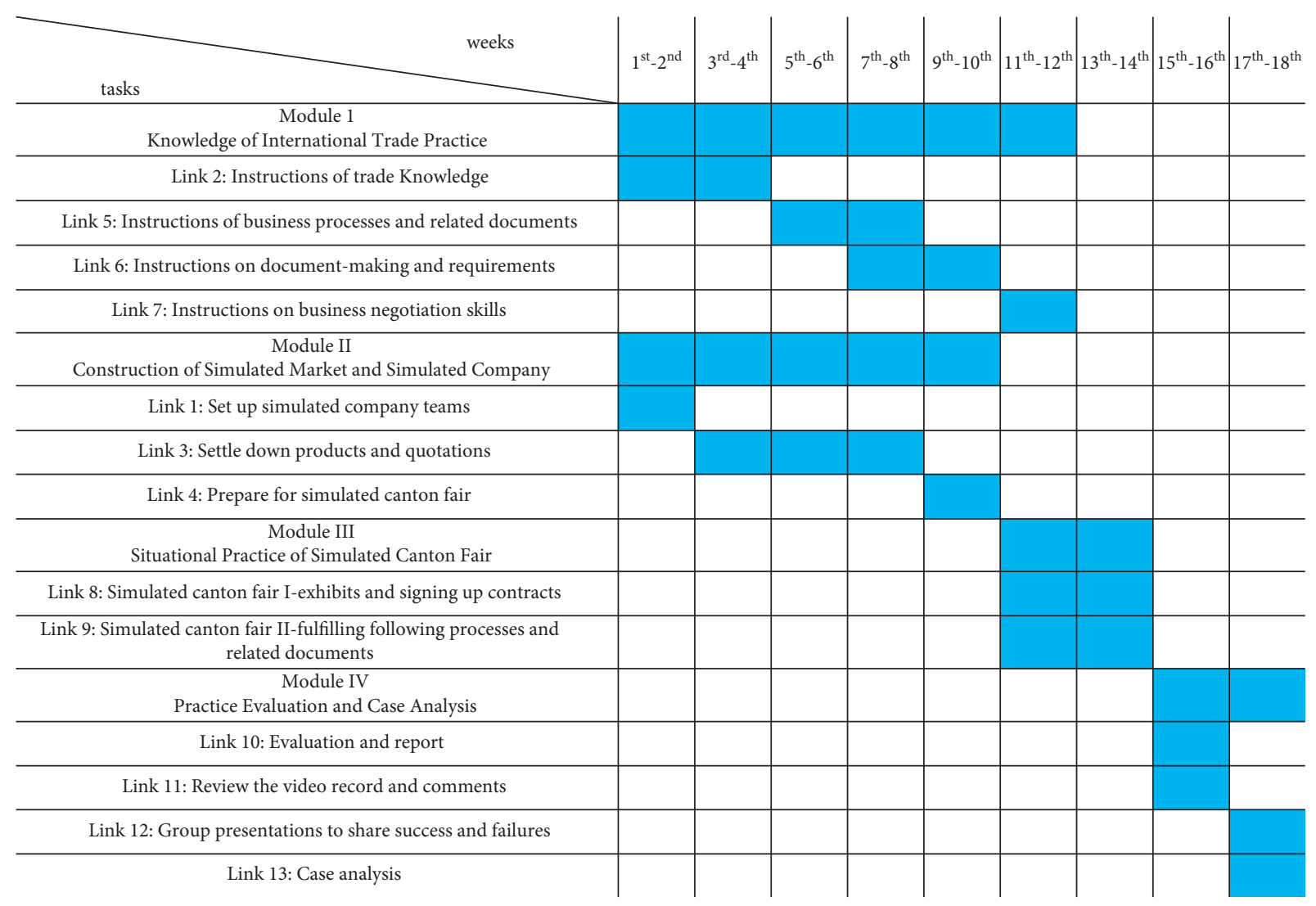

Figure 3: The experiment and innovated teaching plan (Gantt chart).

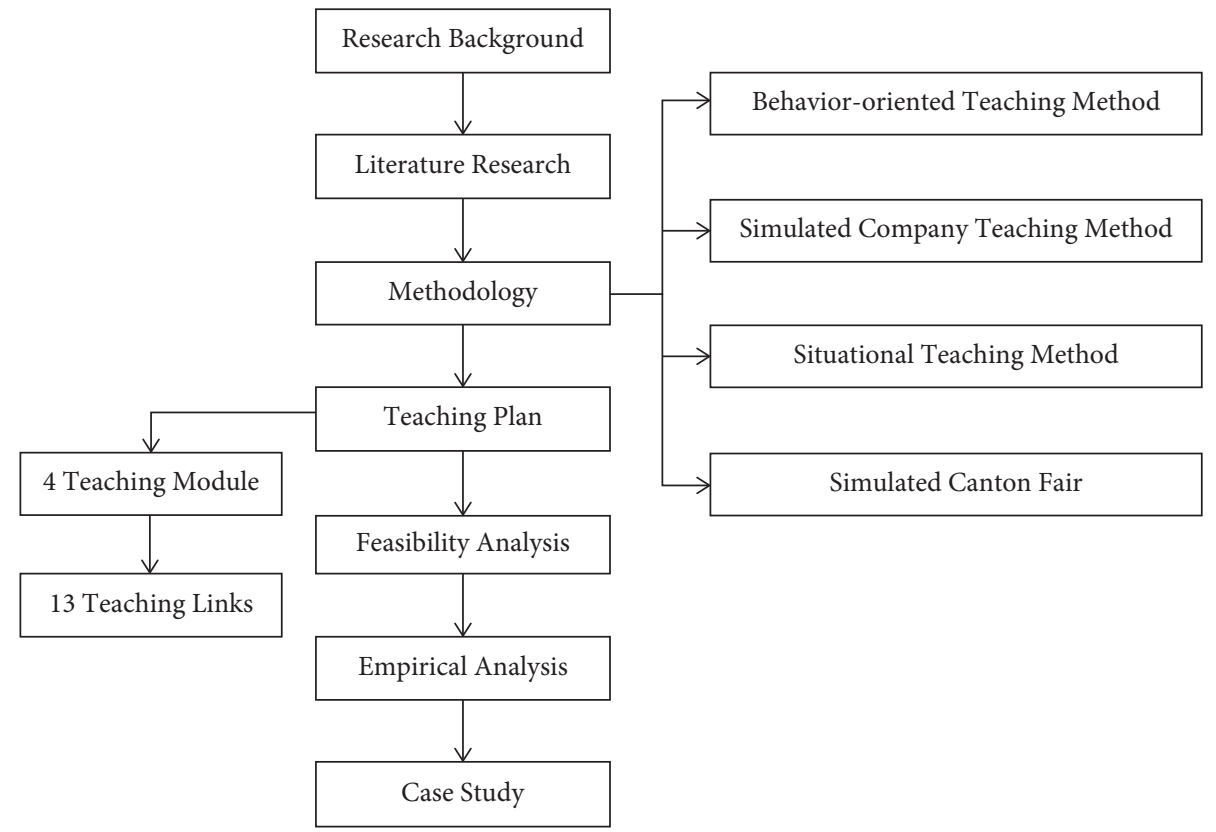

Figure 4: Technical route of the plan.

4.1. 13 Links. Module 1 runs through weeks $1-12$ and includes links 2, 5, 6, and 7. In this stage, the tutor will teach knowledge points such as the international trade process, legal provisions, document filling requirements, and international negotiation skills to support the practical tasks of modules 2, 3, and 4. Module 2 covers links 1, 3, and 4. This section is synchronized with the first module. According to the big data provided by the BDaaS system, teachers and students set up the company type, operation mode, products, and quotation and prepare for the operation of the 
company and the simulated Canton Fair activities with VR technology. Module 3 includes links 8 and 9. The tutor will guide students to complete the tasks from exhibition area layout, business negotiation, and order confirmation to document filling. The big data information provided by the BDaaS system in the early stage will play a key role in the process of simulation, such as product specifications and business negotiations. Module 4 contains links 10, 11, 12, and 13. Students' behavioral data in modules 2 and 3 will be input into BDaaS for analysis, clearance, and in-depth mining. The processed information will provide data for teachers and students to reflect on the whole practice process. The supervisor organizes the students to communicate and summarize in groups and puts forward the summary report to form teaching cases (Figure 3 shows the experiment and innovated teaching plan in Gantt chart and Figure 4 shows the technical route of the plan).

Link 1: set up simulated company teams. Students set up company teams in the first class by random grouping. Each team acts as supplier, buyer, and shipping company. Each group is given a sum of initial capital ( $\$ 100,000$ in our plan). Tutors set a product, but let students decide the product design (In our plan, we set ceramic garden fathers. Tutors should be able to decide the manufacturing cost of the product). Tutors instruct company teams to do market research, product research product design, and packaging design. After market research, company teams get some ideas of design and promotion. Then, they settle their product designs, specifications, weights, packaging, item numbers, and other technical terms. Company teams color print their product designs, and we take them as sample products. Each group should keep secret of their designs.

Link 2: instructions of trade knowledge. Students purposely learn knowledge of international transactions, including international trade flow, trade policy, trade related laws and terms, negotiation, transportation and insurance, payment, customs clearance, and international logistics. They also get to know what operations they need to do.

Link 3: group seminar 1. Before the third week, tutors collect and study all the product designs and play the role of the "invisible hand" of the export product market. After careful examination of product design and their details, tutors carry out individual group seminar and settle down the manufacturing cost for each product of each company team. Then, company team can calculate the FOB price of each product. Company teams must key secret of their manufacturing cost. Tutors also play the role of the "invisible hand" in the sales market in importing country. After a lot of comparison and discussion, tutors determine the sale prices of all the products. Sales prices are kept secret to all students (including the designers).

Link 4: prepare for simulated Canton Fair. Each team prepares for exhibition, including booth design, company logo design, business card design, and product catalogue and product tag.

Link 5: instructions of business processes and related documents. Company teams begin to make empty documents (document samples are given by tutors or loaded from document software.). Major documents include sales contract, bill of lading, insurance policy, bank documents (all with a company title) and quality certificate, quality certificate, and letter of origin (all with an organizational title).

Link 6: group seminar 2. Tutors examine the documents and clarify the requirements of document fulfilling. Tutors give out quotation calculation and set domestic and international fees. Then, company teams can calculate the FOB/ CIF price.

Link 7: instructions on business negotiation skills. Tutors instruct international business skills, related terminologies, business behaviors, and negotiation.

Link 8: simulated Canton Fair I. It is the first part of integrated situational practice. Each group exhibits product samples (color photos). They distribute product catalogues, attract buyers, and sign up sales contract. Each group also sends out buyers to purchase products from other teams and signs up purchase contracts. Company teams cannot buy their own products. Each team must sign up corresponding carriage contract for the product they purchase.

Link 9: simulated Canton Fair II. It is the second part of integrated situational practice. Each team fulfills the trade processes and related documents according to their contracts. Tutor team plays the role of bank, insurance company, and customs.

Link 10: evaluation report. All company team performances are evaluated in dollar value according to their sales profit, purchasing profit (It refers to the profit gained when buyers resell their products they buy in Canton Fair in the importing country.), profit as shipping companies, and other adds and subtracts. They are evaluated, ranked, and reported.

Link 11: review the video record and comments. Students watch the video of their transactions. Tutors announce the evaluation results and make comments.

Link 12: group presentations to share success and failures.

Link 13: case analysis. Tutors choose typical cases for further analysis and help students understand business management risks. Students learn by heart from their own failures.

\section{Conclusion}

With teaching experience of international trade of more than 5 years, 16 classes, and more than 800 students, we find the plan practical and effective in six ways.

First, we receive favorable comments and achieve good teaching results. With the "work-integrated learning" model, our students are enthusiastic in autonomic learning and independent thinking. Tutors are organizers and instructors. Teaching and learning are student-oriented.

Second, "learning by doing" deepens students understanding of trade knowledge and skills. English business environment, real business negotiation, real transaction operations, multiple documents, real competition, complex planning and management, labor division, teamwork, responsibility, short-time decision making, product vision, and budget control, all these in our plan train students the 3-layer capabilities: basic, professional, and comprehensive. 
Third, the DSE of BDaaS gives full play to the teaching links such as knowledge explanation, model construction, behavior guidance, and evaluation improvement, so as to closely link the practical teaching with the development of the industry and cultivate the core skills required by enterprises.

Fourth, BDaaS records the behavioral data of students throughout the activity and gives positive and negative feedback to students' activities through structural analysis, extraction, and summary. Through a series of evaluation report, performance review, group presentation, and case study, students share their harvest of their hard work and deepen their experiences and lessons.

Fifth, role play and teamwork help students know themselves. The big plan must be done by a group. Labor division and cooperation are inevitable. In this process, students get to know their role and contribution in a team. The cooperation between teams to achieve win-win deal also helps them set up a positive, responsible professional attitude. Leadership, cooperativeness, planning, and management responsibilities are key elements for their future occupation.

Sixth, the plan is flexible and extendable. It is not restricted by teaching facilities. University with limited resources can carry out this practical teaching plan. Moreover, this plan is extendable and interacts with other courses. For example, in the present plan, bank is a mere credit intermediary. In the future, we can also add financing function to it. Therefore, company team is not restricted to $\$ 100,000$. They have more access to capital which means they would shoulder higher capital management risk which further train high-level talents.

\section{Data Availability}

The data used to support the findings of this study are available from the corresponding author upon request.

\section{Conflicts of Interest}

The author declares that there are no conflicts of interest.

\section{Acknowledgments}

The author acknowledges the projects titled Under the Condition of "Work-Integrated Learning," Innovation Research on Application-oriented Talents Cultivating Mode of International Trade Major Led by Enterprises (2017GB128), and Under the Background of New Liberal Arts Construction, Research on the Construction of "Foreign Language + International Trade" Informatization Practice and Training Base for Business English Majors Oriented by OBE Education Concept (2021J18).

\section{References}

[1] X. P. Cao, Case Teaching of the Course International Trade Practice: Design, Problems and Reflection, Journal of Wuxi Institute of Commerce, Wuxi, China, 2014.
[2] M. Novikov, S. Zemlyanskaya, and S. Zemlyanskaya, "The procedure of applying special protective measures in foreign trade practice," Vestnik Volgogradskogo gosudarstvennogo universiteta. Serija 3. Ekonomika. Ekologija.vol. 3, no. 3, pp. 79-85, 2014.

[3] M. Yin, The Application of Behavior-Oriented Teaching Approach in the Teaching of International Trade Practice, Science Education Article Collects, Pittsburgh, PA, USA, 2014.

[4] W. U. Feng-Jiao, Application Research on "One Body and Two Wings" Teaching Mode in the Course of "International Trade Practice", Journal of Hubei Correspondence University, Hubei, China, 2014.

[5] L. U. Su-Mei, Project-based Teaching of International Trade Practice Course, Journal of Ningbo University of Technology, Ningbo, China, 2014.

[6] C. Xiao, On the Situational Teaching Mode of International Trade Practice Course in High Vocational Education, Journal of Henan Institute of Science \& Technology, Henan, China, 2014.

[7] X. Yang, "A study of teaching reform of international trade practice at higher ocational colleges," Journal of Liuzhou Teachers College, vol. 20, 2014.

[8] D. M. Huang and T. A. Tang, On the Teaching Reform of International Trade Practice Course in Vocational Colleges, Journal of Zhejiang Textile \& Fashion Vocational College, Zhejiang, China, 2014.

[9] L. I. Ji-Hong, "The study on the course teaching mode in vocational Colleges"Foreign trade document Practice"Combined the"Massive open online Course"and"Flipped classroom"," Higher Education Forum, vol. 20, 2016. 